\title{
A Conjoint Approach to Understanding Online Buyers' Decisions towards Online Marketplaces
}

\author{
Baozhou Lu' ${ }^{1}$ and Song Zhang ${ }^{2}$ \\ 1 Qingdao University, Business School, Qingdao, China, bzlu@qdu.edu.cn \\ ${ }^{2}$ Qingdao University, Business School, Qingdao, China, carolezh@sina.com
}

Received 6 March 2019; received in revised form 8 August 2019; accepted 1 October 2019

\begin{abstract}
The marketplace-based e-commerce is the dominant type so far. Therefore, it is important to understand the decisional attributes and their relevance for online consumers when choosing marketplaces. However, little research is devoted to this issue. This paper outlines seven attributes of marketplace based on three theories, including ease of use, usefulness, logistics service quality, effectiveness of feedback mechanisms, effectiveness of escrow service, effectiveness of information security services, and effectiveness of dispute resolution mechanisms. Via conjoint analysis methodology, we find that for the whole sample effectiveness of dispute resolution is the most important attribute, whereas logistics service quality is the least important one. The results further reveal gender has impacts on the relative strength of each attribute: while male buyers think some attributes (i.e., effectiveness of dispute resolution mechanisms and effectiveness of information security services) are more important than others (i.e., logistics service quality), female buyers consider that each attribute is equally important. This study suggests that institutional theory and technology adoption model offer more relevant theoretical perspective than the logistics service theory for marketplace choice. Though having limitations including focusing on young users in one region, this paper offers several theoretical contributions to research and some insights for practice.
\end{abstract}

Keywords: Online purchase decision, Marketplace choice, Conjoint analysis, Decisional attribute, Institutional mechanisms 


\section{Introduction}

Online marketplaces, such as eBay, Amazon and Airbnb, have dominated current e-commerce economy in this digital era [8], [19], [22], [28], [33]-[34], [42]. There have been hundreds of online marketplaces in the globe and the number is just growing. Competitions among these marketplaces become more and more violent with the emergence of new digital technologies. This calls special attention to an important issue that how buyers make a choice among marketplaces when making online transactions, such as purchasing a product or service. However, the majority of the existing studies have focused on buyers decisions inside of a marketplace [28], [43], [51] or a business-to-consumer (B2C) website [38]-[39], [46], [50], without giving much thought to the decision criteria when considering a choice of an online marketplace for making a transaction. Despite the growing importance and relevance of online marketplaces in digital economy, our knowledge on marketplace-related attributes and their relevance to buyer decisions still remains limited. The lack of knowledge in this area may account for the difficulties faced by a significant number of marketplace sponsors in in establishing and sustaining their marketplaces [8], [16], [63]. This paper aims to address this knowledge gap by: (1) identifying the marketplace-related attributes considered by buyers when making online transactions, and (2) assessing the relative strength of these attributes in the decision-making process with a conjoint analysis approach.

Conjoint analysis is a widely used approach in marketing research that concerns the day-to-day decisions of people wherein they deal with options that simultaneously vary across multiple attributes [53]. It therefore offers a more realistic decision model by allowing subjects to evaluate the option as a whole, which is similar to their actual purchasing situation. It then enables a decomposition of the overall judgment into the partial contribution of stimuli features, and thus help to understand the relative strength of attributes and the trade-offs that a consumer makes when making a purchase decision [58]. Overall, conjoint approach has a number of features that make it superior to compositional approaches such as Likert-type scale measures [24], [53], [57]. First, the trade-off tasks of conjoint analyses are more similar to real choice situations than those where attributes are evaluated separately [23], resulting in a relatively higher predictive validity [57]. Second, since in conjoint analysis subjects choose between multiple reasons to justify any particular decision, conjoint approach can reduce the influences of the social desirability bias [53]. Third, conjoint approach allows an assessment of the relative importance of attributes, thus enabling researchers to evaluate the explanatory power of different theories in a single study [53]. Although conjoint analysis is widely used in marketing research, it has been rarely applied in e-commerce research. When purchasing online, buyers are often faced with different marketplace alternatives. Thus, conjoint analysis allows us to present the respondents a set of profiles that model different marketplace scenarios faced by an online buyer. Responses to these profiles, thus, offer a level of insight not normally available from traditional questionnaire studies [53], [58].

Creation of valid scenarios to be used in conjoint analysis requires the definition of a set of attributes that influence the marketplace choice decision. These attributes, indicated by prior research [44], should also have a solid theoretical basis in order to provide valuable knowledge for making better decisions. To achieve this, we rely on three theories, which have been widely used in studying online purchase decision and are closely related to the marketplace, to identify decision attributes in this study: logistics service quality theory (LSQT) [4], [6], [48]-[49], technology adoption model (TAM) [13]-[14], [20], [26], [67] and institutional mechanism theory (IMT) [8], [17], [22], [43]. First, online transactions often take place in a relatively low trust culture where people have to do business with strangers. To overcome their reluctance to make purchase from unknown sellers, buyers tend to rely on a trustworthy middleman to ensure the security of online transactions [51]. Online marketplaces, as one type of middleman, can guarantee online transactions by offering and implementing institutional mechanisms such as escrow services, online credit card guarantees, and privacy protection that form an appropriate, well ordered, and favorable transactional environment [22], [43]. Thus, IMT should offer us a solid theoretical perspective to understand buyer decisions toward marketplaces, and the attributes of marketplace indicated by IMT are effectiveness of feedback mechanisms, effectiveness of escrow service, effectiveness of information security services, and effectiveness of dispute resolution mechanisms [42], [43]. Moreover, an online marketplace is inherently an integration of the most advance information technologies and thereby can be viewed as one particular type of information system. Thus, buyer choices over online marketplaces should be partially explained by TAM, the mostly adopted theory in understanding user adoptions of information technologies [20]. TAM then suggests two attributes of marketplace from the technological perspective: perceived usefulness and perceived ease of use [20] [26], [67]. Finally, any product purchased online has to be delivered buyers via the logistics system, which is a necessary and essential part of e-commerce. Online marketplace sponsors ensure the quality of logistics service by providing self-managed logistics system or by carefully choosing the logistics partners. Thus, logistics service quality should be one important attributes considered by buyers when choosing marketplace indicated by LSQT [49]. In together, these three theories contribute to uncovering three cornerstones that underpin the success of online marketplace: logistics services, technological supports and institutional mechanisms. The missing of anyone of these three cornerstones might lead to the failure of an online marketplace. Seven attributes, including ease of use, usefulness, logistics service quality, effectiveness of feedback mechanisms, effectiveness of escrow service, effectiveness of information security services, and effectiveness of dispute resolution mechanisms, are finally derived from these theories and empirically tested by means of the conjoint methodology. From the perspective of theory, the research results based on a survey suggest that the most important the strongest theories for understanding buyer decision toward marketplace are the institutional theory and the technology adoption model, while the weakest is the 
logistics service quality theory. Thus, though having some limitations such as focusing on young users and conducted in Chinese context, this study still files the knowledge void by providing a broader theoretical understanding of the motivations of online buyers when considering marketplace alternatives.

The rest of the paper is organized as follows. We fist briefly discuss the concept of online marketplace and the purchase decision process from an online marketplace. Next, we provide a review of the relevant theories for online purchase decision towards marketplaces. We then present the research model and methodology. Finally, we discuss and present implications of the findings for both research and practice.

\section{Online Marketplace and Purchase Decision Process}

Over the last few years, there has been a surge of interest in the concept of "online marketplace" for both the academics and the practitioners. Online marketplaces are multibillion-dollar businesses [24]. In this section, we first introduce the concept of online marketplace and the status quo of research in this area, followed by the analysis on buyers' decisions in online marketplaces.

\subsection{Online Marketplace}

An online marketplace is an online virtual place where buyers and sellers exchange product information and make transactions with the use of internet technologies, including information systems, payment technologies, social applications, visual simulation and other new digital technologies [19], [33], [51]. By bringing together numerous buyers and sellers and by managing transactions automatically, online marketplaces offer more opportunities for both of the transaction parties because of the network effects [31], [55]. Thus, online marketplaces are in essence as the endorsing institutions or transaction intermediaries between buyers and sellers who might have no interactions before [8], [51]. By offering transaction information and establishing reliable institutional context, online marketplaces facilitate transactions between the unseen sellers and buyers [11], [25]. Today, online marketplace has become the most efficient and important model for e-commerce transactions [33]-[34], and the volume of transactions in online marketplaces is explosively expanding [8], [28]. New marketplaces are emerging at an unprecedented rate by exploiting new digital technologies (e.g., the mobile online marketplaces, the social network based marketplaces, and the apps) or by meeting new market needs (e.g., Uber and Didi for transportation services, Airbnb for accommodation services). With the popularity and success of online marketplaces, the academic interest in this area is continually growing [2], [8], [15], [22], [28], [33]-[34], [42]-[43], [47], [51].

One of the main research interests in this area is to study buyer purchase decision inside of an online marketplace, where buyers are especially vulnerable to fraud and other opportunistic behaviors of sellers [28], [34], [52]. Trust, is then suggested in literature, the most fundamental social mechanism that helps diminish complexity and vulnerability that a buyer feels in an online marketplace [20], [34], and thus, as the key facilitator of online transactions [12], [27], [32]. Therefore, studies of online purchase decision are often centered on the concept of trust, trying to uncover the trust-building mechanisms [8], [43], [51] or identify the boundaries of the effects of trust on transaction activity [17], [22]. For instance, Pavlou and Gefen [51] studied the effects of three IT-enabled institutional mechanisms established by online marketplaces on the institution-based trust. Lu et al. [43] confirmed the positive roles of two set of marketplace-related attributes, i.e., IT-enabled institutional mechanisms and social attributes afforded by social technologies, in engendering trust at the institutional level. Although these studies shed light on trust and purchase decision in online marketplaces, they cannot tell us how online buyers make a choice when facing a variety of different online marketplaces. Solutions to this problem become particularly pertinent considering the rising number of online marketplaces in this digital economy (e.g., more and more marketplace apps in smart cellphones) and the fierce competition among them. This calls special attention to buyer decisions towards marketplaces rather than those inside of a marketplace. These two types of decisions are further explained in next section.

\subsection{Purchase Decisions in an Online Marketplace}

The decision making process is a little more complex when buying from online marketplaces than from the online storefronts or e-merchants. Unlike in online storefronts where buyers make transactions directly with one identifiable Internet merchants, in online marketplaces buyers have to deal with both the marketplace and the sellers resided in that marketplace. Therefore, there at least two decisions (shown as Figure 1) faced by buyers when trying to make a purchase from online marketplaces: (1) from which marketplace to make a purchase and (2) whether to transact with the sellers in a specific marketplace if the first decision has been made. As stated in last section, while the second type of decision (Decision 2 in Figure 1) has been extensively explored in literature [8], [43], [47], [51], [67], the first type of decision (Decision 1) is rarely examined. However, the intense competitions among online marketplaces make the first type of decision a significant and pertinent problem today. Only if the marketplace sponsors such as Amazon and Alibaba know buyer preferences in choosing online marketplaces can they take the right countermeasures to improve and sustain their marketplaces [16], [63]. This study then tries to fill the aforementioned knowledge gap by focusing on this untapped type decision in literature with the use of conjoint analysis approach.

Next we turn to the discussion of decision attributes for conjoint analysis method. 


\begin{tabular}{|c|c|}
\hline $\begin{array}{c}\text { Decision 1: } \\
\text { From which marketplace to } \\
\text { purchase? }\end{array}$ & $\begin{array}{l}\text { Decision 2: } \\
\text { Whether to transact with the community of } \\
\text { sellers in a marketplace? }\end{array}$ \\
\hline $\begin{array}{l}\text { This type decision is rarely } \\
\text { examined in current literature. } \\
\text { Attributes considered for Decision } \\
1 \text { are mostly related with the } \\
\text { marketplace per se: } \\
\text { - Institutional mechanisms } \\
\text { - Websites characteristics } \\
\text { - Logistics service quality } \\
\text { - E-Service Quality } \\
-\ldots\end{array}$ & $\begin{array}{l}\text { This type of decision has been extensively } \\
\text { explored in literature. Attributes considered } \\
\text { for Decision } 2 \text { are related with both the } \\
\text { sellers and the marketplace: } \\
\text { - Trust in marketplace } \\
\text { - Trust in sellers } \\
\text { - Institutional mechanisms } \\
\text { - Websites characteristics } \\
\text { - Risk } \\
\text { - ... }\end{array}$ \\
\hline
\end{tabular}

Figure 1: Two types of purchase decisions in online marketplaces

\section{Attributes for Marketplace Decision}

While Decision 2 involves attributes that are related with both marketplaces and the community of online sellers, attributes for Decision 1 should be associated with the marketplace per se to a large extent. The marketplace-related attributes for the current study then can be identified by relying on relevant theories in literature. We take our cue from three theories that have been applied to online purchase decision: logistics service quality theory [6], [49], [68], technology adoption model [8], [20], [26], [67], [69] and institutional mechanism theory [8], [17], [35], [43], [51].

\subsection{Logistics Service Quality Theory and Related Attribute}

Logistics service quality theory roots in service quality research, which has been a priority theme in both marketing and logistics research since the mid of 1980s [54], [60]. Logistics service is viewed an indispensable part of ecommerce. For a process point of view, e-commerce service consists of two dimensions: e-service and logistics service [41]. E-service facilitates online transactions by offering services to buyers with the use internet technologies, such as, searching for product information, placing orders, paying and reviewing. Once online transactions have been made, logistics service is immediately needed to deliver products to buyers. Logistics service can be completed via either the self-managed logistics system or third-party logistics (3PL) system [59]. Therefore, the quality of logistics service offered by online marketplaces is an important part of the online shopping experiences perceived by customers. Logistics service quality (LSQ) has been recognized as an important attribute for enhancing customer satisfaction [49] and customer loyalty [6], [41] in e-commerce. Recent industrial reports showed that logistics service related factors, including delivery speed, reputation and delivery cost, are the major attributes considered by buyers when purchasing online [9]. In general, online marketplace sponsors include LSQ as one of the key indicators for post-purchase evaluation.

Current research generally treats LSQ as a multi-dimensional construct [4], [48]. For instance, Mentzer et al. [48] developed a scale of LSQ that has 9 dimensions including information quality and order quality. Kang and Kim [30] proposed a model of LSQ that covers three dimensions: service outcome quality, service delivery quality and service capability quality. For the purpose of simplification, this study takes the overall logistics service quality (LSQ) as one decision attribute for conjoint analysis. Therefore, one attribute springs out relying from LSQT, namely, LSQ, defined as "the extent to which the logistics systems offered by an online marketplace satisfy the demand of buyers who receive logistics service" [49].

\subsection{Technology Adoption Model and Related Attribute}

E-services in online marketplace are delivered via the IT infrastructures and new digital technologies such as visual simulation and streaming technologies [19] provided by marketplace sponsors. These digital technologies are integrated into and offered via a website or app. Therefore, platform characteristics [67], such as usability, ease of use, interactivity and social presence, have been suggested as key determinants of online purchase decision, satisfaction, and repurchase intention in e-commerce [1], [10], [26], [33], [42], [61].There are quite a few different theoretical perspectives that have contributed a long list of determinants related to website characteristics. Among them, technology acceptance model offers us a more parsimonious way to understand information technology adoption [13]-[14], [26], [67]. An e-commerce website, app or platform is an integration of information and digital 
technologies in essence, and thereby, online purchase decision should be explained in part by the technology acceptance model [20]. Based upon TAM, two technological attributes of online marketplace, namely perceived usefulness (PU) and perceived ease of use (PEOU), are generally recognized to have influences on buyer decision of online transactions [20], [26], [37], [67].

Thus, according to TAM, there are two determinants that we hypothesize that online buyers assess in determining which marketplace for online transactions:

- Usefulness: the utility offered by the information and digital technologies in an online marketplace.

- Ease of use (EOU): the cognitive effort needed to learn and to utilize the information and digital technologies in an online marketplace.

\subsection{Institutional Theory and Related Attribute}

E-commerce activities in online marketplaces are often perceived to be less legally protected and to be at greater risk because information about sellers and products cannot be fully assessed [34], [38], [51]. These negative perceptions such as risk and uncertainty become the major barriers to prevent buyers from engaging online transactions in online marketplaces [34], [52]. In this situation, online marketplaces, as the intermediary between unseen sellers and buyers, have to establish institutional mechanisms to foster buyers' trust and reduce their risk to enhance transaction activity [8], [22], [35]. These IT-enabled institutional mechanisms (e.g., feedback mechanisms, third-party escrow services, and credit card guarantees) provide a certain degree of guarantee and protection for transactions by restricting the ability of a seller to engage in opportunistic behavior [7]-[8], [43], [51]. This institutional perspective [70] has been widely applied to online marketplace research [22], [43], [51]. If these institutional mechanisms are felt to be available and effective in facilitating and securing online transactions [8], [35], the overall transaction environment in online marketplaces will be perceived to be appropriate, well ordered, and favorable for doing personal business [43].

Therefore, prior work generally examined the impacts of the effectiveness of these institutional structures on the institution-based trust and purchase decision [17], [43], [51]. Drawing from institutional mechanism theory, there are four determinants that we hypothesize buyers assess in determining which marketplace for online transactions:

- Effectiveness of feedback mechanisms (EFM): the extent to which the feedback mechanism in an online marketplace is able to provide accurate and reliable information about the sellers. Feedback mechanisms are buyer-driven reputation mechanisms that accumulate and disseminate information and electronic wordof-mouth (eWOM) (e.g., reviews, opinions, ratings, and recommendations) about sellers' past trading behavior and performance [7], [22], [35]. They allow buyers to assess the entire community of sellers in a marketplace by providing an overview of the marketplace and its sellers' past behavior. Thus, effective feedback mechanisms should therefore act as an informal buyer-driven certification system for sellers [7], [35], [51].

- $\quad$ Effectiveness of escrow services (EES): the extent to which the escrow services are able to guarantee that their transactions in a marketplace will be fulfilled in accordance with their expectations [22], [43]. Escrow services is the most adopted e-commerce payment mechanism in which a trusted third party authorizes payment only after the buyer has received and approved the purchased products. They protect buyers from the threats that arise from the opportunistic behaviors of sellers (e.g., offering false product information, fraud and reducing the promised quality of product offerings) by adding a level of control to the transaction [52].

- Effectiveness of information security (EIS): the extent to which the security mechanisms in an online marketplace are able to protect his/her private information from risk of improper or illegal use [43]. Security concerns are one of the major barriers that inhibit online purchase behaviors [38], [65]. Online marketplace sponsors then must invest heavily to reinforce the security mechanisms and technologies to protect buyer private information and privacy.

- Effectiveness of dispute resolution (EDR): the extent to which online dispute resolution services are able to redress buyers' disputes or complaints with sellers in accordance with their expectations [43]. Disputes about online transactions are growing explosively. These disputes must be well resolved so that online buyers and sellers can have full confidence in e-commerce [18], [43], [64]. Online Dispute resolution (ODR), the dispute resolution method supported by new IT and digital technologies, are thought to be more efficient, more cost effective and more flexible way to address complaints against sellers and protect the benefits of buyers after the transaction have been made.

So far, we have identified seven attributes relevant to buyer decision towards online marketplace (Decision 1) by relying upon prior work. These seven attributes are summarized in Table 1. In this study, we are interested in 
understanding the relative weight that buyers give to each attribute in making a decision on which marketplace to purchase from. We believe the conjoint methodology is the corresponding approach to achieve this objective.

Table 1: Attributes for purchase decision towards marketplaces

\begin{tabular}{|c|c|c|c|}
\hline Theory & Attribute & Definition & Levels for Conjoint Analysis \\
\hline $\begin{array}{l}\text { Logistics } \\
\text { Service } \\
\text { Quality } \\
\text { Theory }\end{array}$ & $\begin{array}{l}\text { Logistics } \\
\text { Service } \\
\text { Quality (LSQ) }\end{array}$ & $\begin{array}{l}\text { The extent to which the } \\
\text { logistics systems } \\
\text { offered by an online } \\
\text { marketplace satisfy the } \\
\text { demand of buyers who } \\
\text { receive logistics } \\
\text { service. }\end{array}$ & $\begin{array}{l}\text { - Poor: logistics service quality is significantly lower } \\
\text { than the industry average level in terms of delivery } \\
\text { time, information, tracking information, order } \\
\text { condition, order quality and personnel. } \\
\text { - Moderate: logistics service quality is at the industry } \\
\text { average level. } \\
\text { - Excellent: logistics service quality is significantly } \\
\text { higher than the industry average level. }\end{array}$ \\
\hline \multirow[t]{2}{*}{$\begin{array}{l}\text { Technology } \\
\text { Adaption } \\
\text { Model }\end{array}$} & Usefulness & $\begin{array}{l}\text { The utility offered by } \\
\text { the information and } \\
\text { digital technologies in } \\
\text { an online marketplace. }\end{array}$ & $\begin{array}{l}\text { - Low: the marketplace is unhelpful in assisting } \\
\text { buyers to make an online transaction, such as, } \\
\text { searching for product, saving purchasing time, and } \\
\text { improving productivity. } \\
\text { - Moderate: the marketplace is at the moderate level } \\
\text { in helping buyers to make an online transaction. } \\
\text { - High: the marketplace is very helpful in assisting } \\
\text { buyers to make an online transaction. }\end{array}$ \\
\hline & $\begin{array}{l}\text { Ease of Use } \\
\text { (EOU) }\end{array}$ & $\begin{array}{l}\text { The cognitive effort } \\
\text { needed to learn and to } \\
\text { utilize the information } \\
\text { and digital } \\
\text { technologies in an } \\
\text { online marketplace. }\end{array}$ & $\begin{array}{l}\text { - Hard to use: the marketplace is very difficult to use. } \\
\text { - Moderate: the difficulty to use the marketplace is at } \\
\text { the moderate level. } \\
\text { - Easy to use: the marketplace is very easy to use. }\end{array}$ \\
\hline \multirow{4}{*}{$\begin{array}{l}\text { Institutional } \\
\text { Mechanism } \\
\text { Theory }\end{array}$} & $\begin{array}{l}\text { Effective of } \\
\text { Feedback } \\
\text { Mechanisms } \\
\text { (EFM) }\end{array}$ & $\begin{array}{l}\text { The extent to which the } \\
\text { feedback mechanisms } \\
\text { in an online } \\
\text { marketplace is able to } \\
\text { provide accurate and } \\
\text { reliable information } \\
\text { about the sellers. }\end{array}$ & $\begin{array}{l}\text { - Ineffective: feedback mechanisms cannot provide } \\
\text { buyers accurate and reliable information to assess } \\
\text { the products and sellers. } \\
\text { - Moderate: the effectiveness of feedback } \\
\text { mechanisms is at the moderate level. } \\
\text { - Effective: feedback mechanisms can provide } \\
\text { buyers accurate and reliable information to assess } \\
\text { the products and sellers. }\end{array}$ \\
\hline & $\begin{array}{l}\text { Effectiveness } \\
\text { of escrow } \\
\text { services } \\
\text { (EES) }\end{array}$ & $\begin{array}{l}\text { The extent to which the } \\
\text { escrow services are } \\
\text { able to guarantee that } \\
\text { their transactions in a } \\
\text { marketplace will be } \\
\text { fulfilled in accordance } \\
\text { with their expectations. }\end{array}$ & $\begin{array}{l}\text { - Ineffective: escrow services are not able to } \\
\text { guarantee transactions in the marketplace will be } \\
\text { fulfilled in accordance with buyers' expectations. } \\
\text { - Moderate: the effectiveness of escrow services is } \\
\text { at the moderate level. } \\
\text { - Effective: escrow services are able to guarantee } \\
\text { transactions in the marketplace will be fulfilled in } \\
\text { accordance with buyers' expectations. }\end{array}$ \\
\hline & $\begin{array}{l}\text { Effectiveness } \\
\text { of information } \\
\text { security (EIS) }\end{array}$ & $\begin{array}{l}\text { The extent to which the } \\
\text { security mechanisms in } \\
\text { an online marketplace } \\
\text { are able to protect } \\
\text { his/her private } \\
\text { information from risk of } \\
\text { improper or illegal use. }\end{array}$ & $\begin{array}{l}\text { - Ineffective: security mechanisms are not able to } \\
\text { protect his/her private information from risk of } \\
\text { improper or illegal use. } \\
\text { - Moderate: the effectiveness of security } \\
\text { mechanisms is at the moderate level. } \\
\text { - Effective: security mechanisms are able to protect } \\
\text { his/her private information from risk of improper or } \\
\text { illegal use. }\end{array}$ \\
\hline & $\begin{array}{l}\text { Effectiveness } \\
\text { of dispute } \\
\text { resolution } \\
\text { (EDR): }\end{array}$ & $\begin{array}{l}\text { The extent to which } \\
\text { online dispute } \\
\text { resolution services are } \\
\text { able to redress buyers' } \\
\text { disputes or complaints } \\
\text { with sellers in } \\
\text { accordance with their } \\
\text { expectations. }\end{array}$ & $\begin{array}{l}\text { - Ineffective: online dispute resolution services are } \\
\text { not able to redress buyers' disputes or complaints. } \\
\text { - Moderate: the effectiveness of online dispute } \\
\text { resolution services is at the moderate level. } \\
\text { - Effective: online dispute resolution services are } \\
\text { able to redress buyers' disputes or complaints. }\end{array}$ \\
\hline
\end{tabular}




\section{Research Method}

Since the early 1970s, conjoint analysis has been employed in marketing literature as a major approach for measuring buyers' tradeoffs and preference structures among multi-attributed products and services [23]. In a conjoint analysis, the respondent is presented with a set of potential profiles and asked evaluate the profiles they are shown. Each profile is a combination of product attributes having different levels. By varying the features that are shown to the respondents and observing the responses to the product profiles, the researcher can statistically determinate the relative importance of each attribute in the purchase decision.

In this study, online buyers evaluated a set of hypothetical profiles that described an online marketplace option in terms of the seven attributes identified above. The respondents were asked to rate the likelihood of selecting a marketplace for online transactions given the conditions described to them (on a scale of 0 to 100). Attribute levels were chosen to represent variation that typically occurs in choosing a marketplace for online transactions. The attributes, definitions, and levels of the attributes are shown in Table 1.

\subsection{Instrument Development}

To make sure that the attributes and levels reflected a real-life situation, we employed a pretest of our instrument with five academics in e-commerce field and ten buyers who were experienced in purchasing from the real online marketplaces including Taobao and JD in China. Based on their feedbacks, minor revisions were made to the wording and the levels of these attributes, which are finalized in the form above (Table 1). The pretest allowed us to ensure that the instrument contained no ambiguous attributes and the task was appropriate for online buyers. Further, these two steps also ensured the face and content validity of the profiles of online marketplace [58].

Next, we used the orthogonal factorial design to reduce the number of profiles used in the conjoint analysis [23]. The data quality would severely degrade if each respondent is required to assess every possible combination of the attributes and their levels. Recent research indicated that limiting the number of tasks to 20 does not cause a degradation of data [45]. Utilizing an orthogonal factorial algorithm, we determined that we needed a set of 18 profiles for each respondent to evaluate. After reading each profile, the subjects rated the likelihood of engaging online transactions with these marketplaces (the likelihood of decision was our dependent variable). The likelihood was rated from 0 to 100 , where 0 represent that the subject would not to choose the option and 100 represent that the subject would definitely consider this option. An example of the profiles is illustrated in Appendix A.

\subsection{Sample}

Master of Business Administration (MBA) and senior undergraduate students from a Chinese university were recruited for this study. Subjects are required to have past purchase experiences from online marketplaces and are able to make evaluation based upon the combination of the attributes. A research invitation that contained an introductive message of this study and a link for a web survey was sent via Wechat, the most used social network application in China. Each subject was offered a gift and the chance to get several raffle prizes to stimulate more valid responses. The web survey opened for two weeks in August, 2016. In the end, 173 valid responses were obtained after removing 81 invalid responses, resulting in a valid rate of $68 \%$.

For the conjoint approach, a minimum sample size of 75 is usually recommended. However, there is no clear required minimum sample size [45]. The profile of the respondents is shown in Table 2. All subjects have involved online purchase from online marketplaces before and $74 \%$ of them have at least two years of online purchase experience. Therefore, the subjects are experienced and qualified to rate after assessing the profiles.

As the survey was conducted, most of the respondents (98.8\%) were aged between 20 and 35 . Even though the subjects are mainly students, they without a doubt are the major group purchase consumers in China [9]. The use of students sample for e-commerce research was also advocated in previous studies [21], [66] as they have the opportunity to use the Internet for communication and commercial transactions. Therefore, the data could represent the major part of Internet group purchase customers in China.

Table 2: Sample statistics $(n=173)$

\begin{tabular}{|l|l|l|l|}
\hline Measure & Items & Frequency & Percentage \\
\hline \multirow{3}{*}{ Gender } & Male & 80 & $46.2 \%$ \\
\cline { 2 - 4 } & Female & 93 & $53.8 \%$ \\
\hline \multirow{4}{*}{ Age } & 25 or below & 92 & $53.2 \%$ \\
\cline { 2 - 4 } & $>25$ and $<=30$ & 57 & $32.9 \%$ \\
\cline { 2 - 4 } & $>30$ and $<=35$ & 22 & $12.7 \%$ \\
\cline { 2 - 4 } & 35 and above & 2 & $1.2 \%$ \\
\hline
\end{tabular}




\begin{tabular}{|c|c|c|c|}
\hline \multirow[t]{2}{*}{ Category of Students } & Undergraduate & 90 & $52.0 \%$ \\
\hline & MBA & 83 & $48.0 \%$ \\
\hline \multirow{4}{*}{$\begin{array}{l}\text { Experiences to purchase from an } \\
\text { online marketplace }\end{array}$} & 2 years and below & 45 & $26.01 \%$ \\
\hline & $>2$ years and $<=3$ years & 35 & $20.23 \%$ \\
\hline & $>3$ years and $<=5$ years & 26 & $15.03 \%$ \\
\hline & 5 years and above & 67 & $38.73 \%$ \\
\hline
\end{tabular}

\section{Data Analysis}

The collected data was analyzed with SPSS. We first ran a conjoint analysis against the whole sample. The results are shown in Table 3. Overall, the $R^{2}$ was 87.8 percent, which indicated the attributes used in this research captured a high percentage of the variance associated with the marketplace choice decision. The results allowed us to compare the relative strength of the attributes for online marketplace choices. For example, the relative strength of EOU is 13.2 percent, indicating that EOU accounts for 13.2 percent of the likelihood that an online marketplace will be chosen for making online transactions.

An examination of the columns in Table 3 reveals that the two most important attributes when considering an online marketplace are EDR (19.8 percent) and usefulness (15.5 percent). Collectively, these two attributes account for about 35.4 percent of likelihood for marketplace choice. The least important attribute is LSQ (7.9 percent). A further examination discloses that except EDR (the most important attribute) and LSQ (the least important attribute), there are no significant differences among the relative importance of other attributes. This suggests the relative importance of attributes other than EDR and LSQ are nearly equal.

The last column of Table 3 presents the average score of the relative importance for each theory: 7.9 percent for the LSQS-based attribute, 14.4 percent for TAM-based attributes, and 15.8 percent for the IMT-based attributes. The relative importance of LSQS-based attribute is significantly lower than the TAM-based attributes and the IMT-based attributes.

E-commerce literature suggested that gender is an important factor to influence, or perhaps moderate, the extent and pattern of participation in e-commerce activities [29], [36], [56]. Women are less emotionally satisfied with ecommerce than men, while men have more positive attitudes and are more tolerant to risk toward e-commerce in general [56]. Gender is also suggested to play an important moderating role on e-commerce adoption in literature [29], [62]. Therefore, the perceived relative importance of each attribute on marketplace choice between men and women should be different. We examined these differences by running conjoint analysis over the male sample and the female sample separately in this study. The results are presented in Table 4. An examination of the columns for male sample in Table 4 reveals that the three most important attributes when considering an online marketplace are EDR (24.6 percent), EIS (17.5 percent) and usefulness (15.6 percent). Collectively, these three attributes account for over half of the likelihood (58 percent) that the male respondents will choose an online marketplace. The least important attribute is still LSQ (3.7 percent). The results indicate that for male respondents the relative importance of each attribute on marketplace choice is significantly different.

Similarly, an examination of the columns for female sample in Table 4 discloses that the most the three most important attributes are EDR (16.9 percent), ESS (16.8 percent) and usefulness (15.5 percent). The least important attribute for female sample is still LSQ (10.4 percent). However, the difference of the relative importance between the most important attribute (EDR) and the least attribute (LSQ) is no significantly different. The results indicate that for female respondents all the attributes are equally important.

By comparing the results between the male and female sample in Table 4, we find that male respondents weigh significantly differently from female respondents on four attributes: LSQ (3.7\% VS 10.4\%), EDR (24.6\% VS 16.9\%), EIS (17.5\% VS 13.2\%) and ESS (11.4\% VS 16.8\%). This suggests male and female respondents value the attributes differently when making marketplace choice: while male respondents regard the dispute resolution services and the information security mechanisms as the two most important attributes, female respondents give more weights to the logistics service quality and the escrow service offered by marketplace. Finally, the differences of the relative importance of the TAM-based attributes (Usefulness and EOU) between male and female respondents are not significantly different. 
Table 3: Conjoint analysis results for the whole sample

\begin{tabular}{|l|l|l|l|}
\hline Theories & Attributes & Relative Strength & Average for Each theory \\
\hline \multirow{2}{*}{ LSQS } & LSQ & $7.9 \%$ & $7.9 \%$ \\
\hline \multirow{2}{*}{ TAM } & EOU & $13.2 \%$ & \multirow{2}{*}{$14.4 \%$} \\
\hline & Usefulness & $\mathbf{1 5 . 5 \%}$ & \\
\hline \multirow{4}{*}{ IMT } & EFM & $14.0 \%$ & \multirow{4}{*}{$15.8 \%$} \\
\cline { 2 - 3 } & EES & $14.7 \%$ & \\
\cline { 2 - 3 } & EIS & $14.8 \%$ & \\
\cline { 2 - 3 } & EDR & $\mathbf{1 9 . 8} \%$ & \\
\hline
\end{tabular}

Table 4: Conjoint analysis results between male and female

\begin{tabular}{|c|c|c|c|c|c|}
\hline \multirow{2}{*}{ Theories } & \multirow{2}{*}{ Attributes } & \multicolumn{2}{|c|}{ Relative Strength } & \multicolumn{2}{|c|}{ Average for Each theory } \\
\hline & & Male & Female & Male & Female \\
\hline LSQS & LSQ & $3.7 \%$ & $10.4 \%$ & $3.7 \%$ & $10.4 \%$ \\
\hline \multirow{2}{*}{ TAM } & Usefulness & $15.6 \%$ & $15.5 \%$ & \multirow{2}{*}{$15.1 \%$} & \multirow{2}{*}{$14.0 \%$} \\
\hline & EOU & $14.5 \%$ & $12.4 \%$ & & \\
\hline \multirow{4}{*}{ IMT } & EFM & $12.8 \%$ & $14.8 \%$ & \multirow{4}{*}{$16.6 \%$} & \multirow{4}{*}{$15.4 \%$} \\
\hline & EES & $11.4 \%$ & $16.8 \%$ & & \\
\hline & EIS & $17.5 \%$ & $13.2 \%$ & & \\
\hline & EDR & $24.6 \%$ & $16.9 \%$ & & \\
\hline \multicolumn{2}{|l|}{$\mathrm{R}^{2}$} & $89.8 \%$ & $88.1 \%$ & \multicolumn{2}{|l|}{-} \\
\hline
\end{tabular}

\section{Discussion}

In this section, we first sum up the research findings of this study based on the results above. Next, we discuss and present implications for both research and practice. Finally, the limitations of this research are suggested.

\subsection{Findings}

The results reveal some fundamental notions about how online buyers make marketplace choices. First, in general, the most relative important attribute considered by online buyers when making a marketplace choice is the effectiveness of dispute resolution. Dispute resolution mechanisms, as a kind of after-sale protection mechanisms, are the last but probably the most important procedure to protect the interests of buyers from the malicious behaviors of sellers. When the payment has been done, if buyers find any hidden problems related to the transactions (e.g., false description, counterfeit and shoddy products, post-contractual shirking), they tend to rely on online marketplaces (i.e. the middle man or the intermediary) to resolve their disputes and complaints with online sellers in an effectively, fair and impartial manner. However, if online marketplaces, as the endorsed transactional institution, fail to protect the legitimate rights and interests of buyers at this step, trust in these marketplaces will be deteriorated. Once online buyers don't trust an online marketplace any more, they will give up online purchase or leave for others marketplaces [43]. Thus, our results disclose that online buyers are concerned a little more on the after-sale protection mechanism (i.e. dispute resolution mechanisms) than the pre-sale institutional mechanisms, including the feedback mechanisms, escrow service and information security service. Though these pre-sale institutional mechanisms have been well explored in prior research [22], [51], the post-sale institutional mechanisms have not drawn enough academic interests. This study then suggests the post-sale institutional mechanisms deserve more attention in future.

Second, only one attribute was considered minimally important for online marketplace choice: the logistics service quality (7.9 percent likelihood). Existing research generally views logistics service as a vital part of the e-commerce service and as one critical factor for e-commerce success [40], [41]. However, our results indicate that the logistics service quality is not an important attribute considered by buyers for online marketplace choice. Two plausible reasons are offered as below to clarify the discrepancy. First, unlike traditional survey studies in which respondents rate an item without relating to others, subjects in conjoint approach have to make trade-offs among the attributes and rate based upon the whole profile. This allows conjoint approach studies offer a level of insight not normally available from traditional questionnaire studies [58]. Second, choosing an online marketplace is only the first step to complete an online transaction. Though the logistics service quality is an important part of e-service [41], it might not be an important attribute considered by buyers when making a decision on marketplace choices. In the minds of 
online buyers, logistics services might be more associated with the logistics service provider than the marketplace, and thereby, the quality of logistics services should not be an important attribute of the marketplace.

Third, our results reveal that when considering marketplace choice, male buyers weigh the attributes significantly different from the female buyers. While female buyers give nearly equal relative weight to each attribute, male buyers weigh some attributes more importantly than others. Male buyers are more concerned with the dispute resolution services and the information security mechanisms, but attribute minimally importance to the logistics service quality. Our results suggest that male buyers are more risk-taking, and thereby, they would like to have more confidence in the information provided by the third parties, are more tolerant to deficiencies of the pre-sale mechanisms (e.g., escrow services, feedback mechanisms and logistics services), but are concerned with the post-sale mechanisms (i.e., dispute resolution mechanisms). On the contrary, female buyers are more inclined to assess every aspect of the information, indicating that they are more risk-averse when making online transactions. These findings are in accordance with what were observed in existing work [29], [36], [56], which suggested that male buyers have more positive perceptions towards e-commerce and are more tolerant to the perceived risk and uncertainty, whereas female buyers have more negative feelings about e-commerce and are conservative to make transactions.

Finally, three interesting patterns emerge when the results are viewed on a theory-by-theory basis. First, LSQTbased attribute is not considered especially relevant for marketplace choice. One plausible interpretation may be that with the maturation of the e-commerce, online buyers are capable of distinguishing the logistics service from the service and then can ascribe the quality of logistics service to the logistics provider rather than the marketplace sponsor. Second, the TAM-based attributes and the institutional mechanism theory based attributes are considered more relevant for marketplace choice, suggesting that both technology adoption model [13]-[14], [26], [67] and institutional mechanism theory [7]-[8], [43], [51] are two appropriate theoretical lenses for understanding the decision towards the marketplace. Third, no one theoretical lens dominates the marketplace choice decision when considering all three theories in together, suggesting that the phenomenon of marketplace choice should be best viewed from a contingency perspective. Rather, it is best explained by utilizing certain attributes from several different theories for different genders. For male buyers, the appropriateness of marketplace choice mainly varies based upon the effectiveness of dispute resolution mechanisms, the usefulness and the effectiveness of information security mechanisms. For male buyers, the appropriateness mainly depends upon the effectiveness of dispute resolution mechanisms, the usefulness and the effectiveness of feedbacks mechanisms.

\subsection{Implications for Research}

This study has a number of implications for future research. First, we have applied the conjoint approach to study buyer decision in e-commerce research. Despite the extensive applications of this method in marketing research, conjoint analysis has been rarely used in the field of information systems [58] and e-commerce. Followed Schwarz et al. [58], we also believe that the conjoint methodology is both practically relevant (as these results are easily digestible to practitioner audiences) and academically rigorous (as the attributes are theoretically based and have implications for how we theorize about decisions on marketplace choice). Thus, we encourage further application of the methodology in understanding many aspects decisions in e-commerce, online marketplace and online community research.

Next, theoretically, the results suggest a number of implications about the relative relevance of theories in understanding decisions of online buyers. The strongest theories are the institutional mechanism theory [7]-[8], [43], [51] and the technology adoption model [13]-[14], [26], [67] while the weakest is the logistics service quality theory [54], [60]. This suggests that online buyers are more concerned with the institutional mechanisms established afforded by IT and digital technologies to safeguard online transactions [8], [43] and the utility of technologies offered by the marketplace [67], but less concerned with the logistics service quality. From another perspective, this reflects the maturity of e-commerce at present. Online buyers are experienced and have the abilities to distinguish the responsibilities of each party (e.g., marketplace sponsors, logistics service providers, online sellers) in e-commerce.

Third, in this work, we offer a more comprehensive model of purchase decision in online marketplace by dividing the decision process into two steps: decision over the marketplace choice (decision 1), and purchase decision in a selected marketplace (decision 2). Then we focus on the first type of decision (marketplace choice) by outlining 7 attributes derived from three theories that we hypothesized to influence a buyer's decision at the marketplace level. In doing this, we not only have examined the impacts of the marketplace-related attributes on decisions of online buyers, but also have contributed a few important theory-based factors that can be further explored in future research.

Finally, we further explore the impacts of gender on the decision of buyers when considering marketplace choice. The results reveal a significant structural difference of the relative importance of attributes between male and female buyers: while male buyers think that some attributes are more important than others, female buyers consider that each attribute is equally important. Thus, this study confirms the impacts of gender on buyers' decisions suggested in prior research [36], [56]. With the new development of e-commerce towards social commerce and mobile commerce, the role of gender on decision of online buyers in these new areas should draw more research interests. Thus, we here call more attention the effects of gender in in future e-commerce studies. 


\subsection{Implications for Practice}

The results also offer a few implications for the marketplace sponsors. First, institutional mechanisms, as the trustbuilding tools, have got a tremendous amount of investments from the marketplace sponsors [22]. However, our results suggest that the marketplace sponsors probably ought to set different investing priorities for different institutional mechanisms. In contrast to the pre-sale mechanisms such as the feedback mechanisms and the escrow services, the post-sale mechanisms (i.e. the dispute resolution mechanisms) are relatively more important for marketplace choice of online buyers. Thus, to gain a competitive advantage, online marketplace sponsors should put more investment in enhancing the post-sale mechanisms like the dispute resolution rather than equally investing on each institutional mechanism.

Second, our results disclose that the logistics service quality is the least important attribute for online byers to marketplace choice. However, this does not simply mean that logistics services are not important for the overall of the online purchasing experience of buyers. It might be because of that online buyers have not directly related the logistics services with the marketplace. This means that online marketplace sponsors should be very careful in interpreting and applying this finding to their logistics strategy. If they plan to build the self-owned logistics systems, the marketplace sponsor should by various means to help online buyers to relate the logistics services with the marketplace and take the logistics services as one key attribute of marketplace for commercial propaganda. And if they plan to rely on the third parity logistics systems, the marketplace sponsor should let the buyers be clearly aware of the situation, as well as enhance the controls and monitoring over the behaviors of the logistics service providers.

Finally, the marketplace sponsors should pay attention to the differences between male and female buyers, and should adjust their strategies in institutional mechanism investment. For instance, for the products (or subpages) that target on male buyers, the marketplace sponsors should pay more attention to the institutional mechanisms like the dispute resolution mechanisms and information security mechanisms, whereas for the products that target on female buyers (or subpages) that target on female buyers, they should focus on providing a full set of institutional mechanisms.

\subsection{Limitations}

Like any empirical research, this work has limitations. First, we selected 7 theoretically derived attributes that were hypothesized to impact buyer' marketplace choices. Although these attributes are grounded from three theories for marketplace research, we recognize that other latent attributes influence the marketplace choice and could indicate different weightings of these (and other) attributes. Second, although we have considered a set of three theories that are relevant to marketplace choices, we cannot include all other important theories in this single study, e.g., social presence theory [21], [42]-[43] and social capital theory [3], [5]. We encourage future research to study marketplace choice by exploring other important theoretical perspectives. Third, MBA and undergraduate student samples were used in this study. While the use of student samples for e-commerce research was advocated in previous studies [21], [66], the sample may not represent actual buyers of online marketplaces. Students are more educated and more familiar with the use of new technologies like e-commerce. Therefore, their perceptions on online marketplace might be different from those of which are less educated and less familiar with new technologies, such as aged people and rural residents. Fourth, the attributes are measured as perceptions in this study. Although it is each buyer's own perception of marketplace that determines his/her transaction decision making, it should be noted that the perception is a fuzzy concept and some perception is more complex and difficult to be measured than others. For example, usefulness of marketplace in this study could be a very fuzzy concept that the respondents have troubles to measure since online marketplace is inherently a complex tool. Thus, the findings of this research might be confounded. This limitation might be overcome by dividing usefulness into several more concrete sub-attributes such as facilitating conditions, hedonic motivation [67] or availability. Finally, caution should be taken when making generalizations from a single study, particularly when this study was conducted mainly in Chinese culture background. The effects of the marketplace-related attributes may be different in another broader institutional, societal, and cultural environment. Therefore, the results might not be simply generalized to other cultural contexts.

\section{Conclusion}

To better understand buyer decision on marketplace choice, we outline 7 marketplace-based attributes by drawing upon three theories and the conjoint analysis methodology. We believe this study offers more profound understandings on online purchase decision in online marketplaces. First, it reveals the relative importance of each attribute on marketplace choice, and thus, suggests setting different investing priority for each attribute based its importance. Second, it examines the impacts of gender on decision over marketplace choice, and thereby, indicates that the marketplace sponsors should tune their marketplace strategies according to the genders of their buyers. Finally, this study suggests the relevance of different theories on decision of marketplace choice: the institutional theory and technology adoption model are more relevant in explaining buyer preferences on marketplace choice than the logistics service quality theory. In doing this, this study not only offers insightful implications for existing online marketplace research but provides some practical advice for online marketplace sponsors. 


\section{Acknowledgments}

This work is supported by the National Social Science Fund of China (Grant No. 16BGL075) and the Ministry of Education of Humanities and Social Science project (Grant No. 19YJA630115). The authors are also extremely grateful to the editors and the three anonymous reviewers for their insightful comments on this paper.

\section{References}

[1] A. Angriawan and R. Thakur, A parsimonious model of the antecedents and consequence of online trust: An uncertainty perspective, Journal of Internet Commerce, vol. 7, no. 1, pp. 74-94, 2008.

[2] S. Ba and P. A. Pavlou, Evidence of the effect of trust buliding technology in electronic markets: Price premiums and buyer behavior, MIS Quarterly, vol. 26, no. 3, pp. 243-268, 2002.

[3] H. H. Bauer and M. Grether, Virtual community: its contribution to customer relationships by providing social capital, Journal of Relationship Marketing, vol. 4, no. 1/2, pp. 91-109, 2005.

[4] C. C. Bienstock and M. B. Royne, Technology acceptance and satisfaction with logistics services, International Journal of Logistics Management, vol. 21, no. 2, pp. 271-292, 2010.

[5] A. Blanchard and T. Horan, Virtual communities and social capital, Social Science Computer Review, vol. 16, no. 3, pp. 293-307, 1998.

[6] R. Bouzaabia, O. Bouzaabia and A. Capatina, Retail logistics service quality: A crosscultural survey on customer perceptions, International Journal of Retail \& Distribution Management, vol. 41, no. 8, pp. 627-647, 2013.

[7] Z. A. Bulut and A. N. Karabulut, Examining the role of two aspects of ewom in online repurchase intention: An integrated trust-loyalty perspective. Journal of Consumer Behaviour, vol. 17, no. 4, 407-417, 2018.

[8] A.Y. L. Chong, E. Lacka, L. Boying, and H.K. Chan, The role of social media in enhancing guanxi and perceived effectiveness of e-commerce institutional mechanisms in online marketplace, Information and Management, vol. 55, no. 5, pp. 621-632, 2018.

[9] CNNIC. (2015) China internet purchase market research report. CNNIC. [Online]. Available: http://www.cnnic.net.cn/hlwfzyi/hlwxzbg/dzswbg/201606/P020160721526975632273.pdf.

[10] J. Collier and C. Bienstock, Measuring service quality in e-retailing, Journal of Service Research, vol. 8, no. 3, pp. 260-275, 2006.

[11] D. Crusciel and F. M. Zahedi, Seller-based vs. buyer-based Internet intermediaries: A research design, in Proceedings of 4th Americas Conf. Inform. Systems, Milwaukee, WI, 1999, pp. 241-243.

[12] R. Davis, M. Buchanan-Oliver and R. Brodie, Relationship marketing in electronic commerce environments, Journal of Information Technology, vol 14, pp. 319-331,1999.

[13] F. D. Davis, Perceived usefulness, perceived ease of use and user acceptance of information technology, MIS Quarterly, vol. 13, no. 3, pp. 319-340, 1989.

[14] F. D. Davis, R. P. Bagozzi and P. R. Warshaw, User acceptance of computer technology: A comparison of two theoretical models, Management Science, vol. 35, no. 8, pp. 982-1003, 1989.

[15] C. Dellarocas, The digitization of word-of-mouth: Promise and challenges of online feedback mechanisms, Management Science, vol. 49, no. 10, pp. 1407-1424, 2003.

[16] T. Eisenmann, G. Parker and M. W. van Alstyne, Strategies for two-sided markets, Harvard Business Review, vol. 84, no. 10, pp. 92-101, 2006.

[17] Y. Fang, I. Qureshi, H. Sun, P. McCole, E. Ramsey, and K. H. Lim, Trust, satisfaction, and online repurchase intention: the moderating role of perceived effectiveness of e-commerce institutional mechanisms, MIS Quarterly, vol. 38, no. 2, pp. 407-427, 2014.

[18] F. Galves, Virtual justice as reality: Making the resolution of e-commerce disputes more convenient, legitimate, efficient, and secure, Journal of Law, Technology \& Policy, vol. 1, pp. 1-68, 2009.

[19] W. Gao, Y. Liu, Z. Liu, and J. Li, How does presence influence purchase intention in online shopping markets? An explanation based on self-determination theory, Behaviour \& Information Technology, vol. 37, no. 8, pp. 786-799, 2018.

[20] D. Gefen, E. Karahanna and D. W. Straub, Trust and TAM in online shopping: An integrated model, MIS quarterly, vol. 27, no. 1, pp. 51-90, 2003.

[21] D. Gefen and D. W. Straub, Consumer trust in B2C e-commerce and the importance of social presence: Experiments in e-products and e-services, Omega, vol. 32, no. 6, pp. 407-424, 2004.

[22] D. Gefen and P. A. Pavlou, The boundaries of trust and risk: the quadratic moderating role of institutional structures, Information Systems Research, vol. 23, no. 3-2, pp. 940-959, 2012.

[23] P. E. Green and V. Srinivasan, Conjoint analysis in marketing: New developments with implications for research and practice, Journal of Marketing, vol. 54, no. 4, pp. 3-19, 1990.

[24] P. E. Green, A. M. Krieger and Y. Wind, Thirty years of conjoint analysis: Reflections and prospects, Interfaces, vol. 31, pp. 56-73, 2001.

[25] V. Grover and J. T. C. Teng, E-commerce and the information market, Communications of the ACM, vol. 44, no. 4, pp. 79-86, 2001. 
[26] J. M. Hansen, G. Saridakis and V. Benson, Risk, trust, and the interaction of perceived ease of use and behavioral control in predicting consumers' use of social media for transactions, Computers in Human Behavior, no. 80, pp. 197-206, 2018.

[27] D. L. Hoffman, T. P. Novak and M. Peralta, Building consumer trust online, Communications of the ACM, vol. 42, no. 4, pp. 80-85, 1999.

[28] I. B. Hong and $\mathrm{H}$. Cho, The impact of consumer trust on attitudinal loyalty and purchase intentions in B2C emarketplaces: Intermediary trust vs. seller trust, International Journal of Information Management, vol. 31, pp. 469-479, 2011.

[29] Y. Hwang, The moderating effects of gender on e-commerce systems adoption factors: An empirical investigation, Computers in Human Behavior, vol. 26, no. 6, pp. 1753-1760, 2010.

[30] G. D. Kang and Y. D. Kim, An analysis of the measurement of the shipping service quality, Asian Journal of Shipping \& Logistics, vol. 25, no.1, pp. 41-55, 2009.

[31] S. Kaplan and M. Sawhney, E-hubs: the new b2b marketplaces, Harvard Business Review, vol. 78, no. 3, pp. 97-103, 214, 2000.

[32] P. Keen, G. Ballance, S. Chan, and S. Schrump, Electronic Commerce Relationships: Trust by Design. Englewood Cliffs, NJ: Prentice Hall, 1999.

[33] M. S. Kim and J. H. Ahn, Management of trust in the e-marketplace: the role of the buyer's experience in building trust, Journal of Information Technology, vol. 22, no. 2, pp. 119-132, 2007.

[34] G. Kim and H. Koo, The causal relationship between risk and trust in the online marketplace: A bidirectional perspective, Computers in Human Behavior, no. 55, part B, pp.1020-1029, 2016.

[35] S. Kim, J. Kandampully and A. Bilgihan, The influence of eWOM communications: An application of online social network framework, Computers in Human Behavior, no. 80, pp. 243-254, 2018.

[36] H. Kwak, R. J. Fox and G. M. Zinkhan, What products can be successfully promoted and sold via the internet?, Journal of Advertising Research, vol. 42, no.1, pp. 23-38, 2002.

[37] M. Law, R. Kwok and M. Ng., An extended online purchase intention model for middle-aged online users, Electronic Commerce Research \& Applications, vol. 20, pp. 132-146, 2016.

[38] H. G. Lee, Do electronic marketplaces lower the price of goods? Communications of ACM, vol. 41, no.1, pp. 7380, 1998.

[39] M. K. O. Lee and E. Turban, A trust model for consumer internet shopping, International Journal of Electronic Commerce, vol. 6. No.1, pp. 75-91, 2002.

[40] H. L. Lee and S. Whang, Winning the last mile of e-commerce, MIT Sloan Management Review, vol. 42, no. 4, pp. 54-62, 2001

[41] Y. Lin, J. Luo, S. Cai, S. Ma, and K. Rong, Exploring the service quality in the e-commerce context: A triadic view, Industrial Management \& Data Systems, vol. 116, no. 3, pp. 388-415, 2016.

[42] B. Lu, W. Fan and M. Zhou, Social presence, trust, and social commerce purchase intention: An empirical research, Computers in Human Behavior, vol. 56, pp. 225-237, 2016.

[43] B. Lu, Q. Zeng and W. Fan, Examining macro-sources of institution-based trust in social commerce marketplaces: An empirical study, Electronic Commerce Research \& Applications, vol. 20, pp. 116-131, 2016.

[44] G. Lord and J. Maher, Alternative information-processing models and their implications for theory, research, and practice, Academy of Management Review, vol. 15, no. 1, pp. 9-28, 1990.

[45] D. McCullough, A user's guide to conjoint analysis, Marketing Research, vol. 14, no. 2, pp. 18-24, 2002.

[46] D. H. McKnight, V. Choudhury and C. Kacmar, Developing and validating trust measures for E-commerce: An integrative typology, Information Systems Research, vol.13, no. 3, pp. 334-359, 2002.

[47] S. Meents and T. Verhagen, Reducing consumer risk in electronic marketplaces: The signaling role of product and seller information, Computers in Human Behavior, no. 86, pp. 205-217, 2018

[48] J.T. Mentzer, D. J. Flint and J. L. Kent, Developing a logistics service quality scale, Journal of Business Logistics, vol. 20, no. 1, pp. 9-32, 1999

[49] J. T. Mentzer, D. J. Flint and G. T. M. Hult, Logistics service quality as a segment customized process, Journal of Marketing, vol. 65, no. 4, pp. 82-104, 2001.

[50] R. Olbrich and C. Holsing, Modeling consumer purchasing behavior in social shopping communities with clickstream data, International Journal of Electronic Commerce, vol. 16, no. 2, pp.15-40, 2011.

[51] P. A. Pavlou and D. Gefen, Building effective online marketplaces with institution-based trust, Information Systems Research, vol. 15, no. 1, pp. 37-59, 2004.

[52] P. A. Pavlou, H. Liang and Y. Xue, Understanding and mitigating uncertainty in online environments: A principal-agent perspective, MIS Quarterly, vol. 31, no. 1, pp. 105-136, 2007.

[53] E. Pelzer, The potential of conjoint analysis for communication research, Communication Research Reports, vol. 36, no. 2, pp. 136-147, 2019.

[54] R. G. Richey, P. J. Daugherty and A. Roath, Firm technological readiness and complementarity: Capabilities impacting logistics service competency and performance, Journal of Business Logistics, vol. 28, no. 1, pp. 195228, 2007

[55] J. C. Rochet and J. Tirole, Platform competition in two-sided markets,Journal of the European Economic Association, vol. 1, no.4, pp. 990-1029, 2003.

[56] S. Rodgers and M. A. Harris, Gender and e-commerce: An exploratory study, Journal of Advertising Research, vol. 43, no. 3, pp. 322-329, 2003.

[57] H. Sattler and S. Hensel-Börner, A comparison of conjoint measurement with selfexplicated approaches, in Conjoint Measurement. Methods and Applications (A. Gustafsson, A. Herrmann and F. Huber, Eds.). Berlin, Germany: Springer, 2007, pp. 67-76. 
[58] A. Schwarz, R. Hirschheim, B. Jayatilaka, and T. Goles, A conjoint approach to understanding IT application services outsourcing, Journal of the Association for Information Systems, vol. 10, no. 10, pp. 748-781, 2009.

[59] J. Semeijn, A. C. R. van Riel, M. J. H. van Birgelen, and S. Streukens, E-services and offline fulfilment: How eloyalty is created, Managing Service Quality, vol. 15, no. 2, pp. 182-194, 2005.

[60] N. Shet, S. G. Deshmukh and P. Vrat, A conceptual model for quality of service in the supply chain, International Journal of Physical Distribution \& Logistics Management, vol. 36, no.7, pp. 547-575, 2006.

[61] P. N. Sindhuja and S. G. Dastidar, Impact of the factors influencing website usability on user satisfaction, The IUP Journal of Management Research, vol. 8, no. 12, pp. 54-66, 2009.

[62] C. V. Slyke, F. Bélanger, R. D. Johnson, and R. Hightower, Gender-based differences in consumer ecommerce adoption, Communications of the Association for Information Systems, vol. 26, no. 1, pp. 17-34, 2010.

[63] B. Tan, S. L. Pan, X. Lu, and L. Huang, The role of is capabilities in the development of multi-sided platforms: The digital ecosystem strategy of alibaba.com, Journal of the Association for Information Systems, vol. 16, no. 4, pp. 248-280, 2015.

[64] O. Turel, Y. Yuan and C. E. Connelly, In justice we trust: Predicting user acceptance of e-customer services, Journal of Management Information Systems, vol. 24, no. 4, pp. 123-151, 2008.

[65] G. J. Udo, Privacy and security concerns as major barriers for e-commerce: A survey study, Information Management \& Computer Security, vol. 9, no., 4, pp. 165-174, 2001.

[66] R. Walczuch and H. Lundgren, Psychological antecedents of institution-based consumer trust in e-retailing, Information \& Management, vol. 42, no. 1, pp. 159-177, 2004

[67] I. B. Yahia, N. Al-Neama and L. Kerbache, Investigating the drivers for social commerce in social media platforms: Importance of trust, social support and the platform perceived usage, Journal of Retailing and Consumer Services, no. 41, pp. 11-19, 2018.

[68] Y. Yang, P. Humphreys and R. Mclvor, Business service quality in an e-commerce environment, Supply Chain Management: An International Journal, vol. 11, no. 3, pp. 195-201, 2006.

[69] B. Yoo and N. Donthu, Developing and validating a multidimensional consumer-based brand equity scale, Journal of Business Research, vol. 52, no. 1, pp. 1-14, 2001.

[70] L. Zucker, Production of trust: Institutional sources of economic structure, 1840-1920, Research in Organizational Behavior, vol. 8, no. 1, pp. 53-111, 1986. 


\section{Appendix A: Example of Conjoint Profile}

If you were considering an online marketplace to make online purchases, and the marketplace:

- Offers logistics services that are significantly lower than the industry average level in terms of delivery time, information, tracking information, order condition, order quality and personnel.

- Is unhelpful in assisting buyers to make an online transaction, such as, searching for product, saving purchasing time, and improving productivity.

And,

- Is very difficult to use

- Offers moderate level of feedback mechanisms

- Offers ineffective escrow services that are not able to guarantee transactions in the marketplace will be fulfilled in accordance with buyers' expectations

- Offers very effective security mechanisms that are able to protect his/her private information

- Offers ineffective online dispute resolution services that are not able to redress buyers' disputes or complaints.

What is the likelihood that you would use this marketplace for online transactions?

Please Rate the likelihood from 1 to 100 , where 0 means that you would not to choose this option and 100 means that you would definitely consider this option. You may use a number anywhere between 0 and 100 . 